\title{
Colloidal and Immobilized Nanoparticles of Lead Xanthates
}

\author{
Sergey A. Vorobyev, ${ }^{\dagger}$ Svetlana V. Saikova, ${ }^{\ddagger}$ Svetlana A. Novikova, ${ }^{\dagger}$ Olga Yu. Fetisova, ${ }^{\dagger}$ \\ Sergey M. Zharkov, ${ }^{\ddagger}, \S$ Alexander S. Krylov, ${ }^{\S(0)}$ Maxim N. Likhatski, ${ }^{\dagger}$ and Yuri L. Mikhlin* ${ }^{* \dagger}$
}

†Institute of Chemistry and Chemical Technology, Federal Research Center "Krasnoyarsk Scientific Center" of the Siberian Branch of the Russian Academy of Sciences, Akademgorodok, 50/24, Krasnoyarsk 660036, Russia

${ }^{\ddagger}$ Siberian Federal University, Svobodny pr. 79, Krasnoyarsk 660041, Russia

${ }^{\S}$ Kirensky Institute of Physics, Federal Research Center "Krasnoyarsk Scientific Center" of the Siberian Branch of the Russian Academy of Sciences, Akademgorodok 50/38, Krasnoyarsk 660036, Russia

\section{Supporting Information}

ABSTRACT: Although nanoparticles of heavy metal xanthates and their hydrosols can play important roles in froth flotation, environmental issues, analytics, and manufacturing of metal sulfide nanocomposites, they have received little attention. We studied colloidal solutions and immobilized particles prepared via interaction of aqueous lead nitrate with alkyl xanthates applying UV-vis absorption spectroscopy, dynamic light scattering, zeta potential measurement, thermogravimetry analysis, Fourier transform infrared spectroscopy, Raman scattering, X-ray photoelectron spectroscopy, atomic force microscopy, and transmission electron microscopy. The hydrodynamic diameter of colloidal particles of $\mathrm{Pb}(\mathrm{SSCOR})_{2}$ decreased from 500 to $50 \mathrm{~nm}$ with an increase in the alkyl radical length and the initial xanthate to lead ratio $(\mathrm{X} / \mathrm{Pb})$; the zeta potential magnitude varied similarly, although it remained negative. The effect of $\mathrm{pH}$ in the range of $4.5-11$ was minor, but the colloids produced using excess of $\mathrm{Pb}^{2+}$ in alkaline media were close to $\mathrm{PbX}$ and decomposed much easier than $\mathrm{PbX}_{2}$. The uptake of lead xanthates on supports was generally low because of negative charges of the colloids; however, 50-100 nm thick $\mathrm{PbX}_{2}$ films were deposited on $\mathrm{PbS}$ and $\mathrm{SiO}_{2}$ from the media of $\mathrm{X} / \mathrm{Pb}<2$ and $\mathrm{pH}<9$ because of preadsorption of $\mathrm{Pb}^{2+}$, while nanorods formed on highly oriented pyrolytic graphite.

\section{INTRODUCTION}

Heavy metal salts of xantic acid (the O-ester of carbonodithionic acid) $\mathrm{M}(\mathrm{SSCOR})_{n}$, where $\mathrm{M}$ is a metal cation, $\mathrm{R}$ is an alkyl group, and $n=1,2$, or 3 , are utilized in the production of cellulose, rubber, pesticides, lubricants, and so forth, for example. $^{1-4}$ Xanthates of lead and transition metals are prospective precursors to nanoparticles and films of metal sulfides, allowing a low-temperature, between 100 and $200{ }^{\circ} \mathrm{C}$, in situ preparation of nanoparticulate sulfides within the polymer matrix for photovoltaics, sensors, and so forth. ${ }^{5-14}$ Xanthates have been proposed as capping ligands in the synthesis of metal nanoparticles and self-assembled monolayers alternative to thiols. ${ }^{14-16}$ Xanthates of alkali metals are widely used for the precipitation and separation of heavy metals in mineral processing, hydrometallurgy, water treatment, analytical practice, ${ }^{1,17,18}$ and, first of all, as collectors in froth flotation of metal sulfide ores. ${ }^{19}$ Water-insoluble xanthates of lead, copper, and some other metals likely emerge as colloidal or surface species in the reaction between the xanthate collector and aqueous cations in the flotation slurries, and their interaction with mineral surfaces is important for understanding the flotation mechanisms and performance. ${ }^{19-30}$ The ultrafine xanthate entities are also possible carriers of lead and heavy metals in wastewaters and natural surface waters, along with metal sulfide colloids ${ }^{31-37}$ or as their precursors. It was demonstrated ${ }^{36,37}$ that the yield of sulfide mineral ultrafines in the mineral processing is not negligible, and their total amounts can be very significant because of large volumes of the ores; moreover, the concentrations of $\mathrm{Pb}$-bearing colloids in environmental waters can be higher than that of aqueous lead ions. ${ }^{31-33}$

Although there are a number of studies on the structure and behavior of metal xanthates, ${ }^{1,12,38-47}$ colloidal and nanoscale metal xanthates having the characteristics different from the bulk materials, which can arise in the technological and environmental media, have received little attention. Recently, we examined the formation of colloidal copper xanthate particles in the reaction of aqueous solutions of cupric sulfate and various potassium xanthates ${ }^{47}$ and found, in particular, that $\mathrm{CuX}$ nanoparticles incorporated about 15 wt \% of dixanthogen; the colloids produced with excessive xanthate had a high negative zeta potential magnitude, lower diameter, and higher

Received: March 26, 2019

Accepted: June 21, 2019

Published: July 1, 2019 
aggregative stability than the ones charged positively at the overstoichiometric excess of cupric ions. The aim of the current research was to study colloidal and immobilized products of the interaction of aqueous $\mathrm{Pb}^{2+}$ cations and various potassium xanthates under conditions, which are of interest for mineral processing, synthesis of PbS-based nanomaterials, and environmental concerns. Serious consideration was given to the effect of $\mathrm{pH}$ and to the species arising at high $\mathrm{pHs}$, in particular, possible formation and behavior of lead hydroxy xanthate. $^{20-25}$

\section{RESULTS}

2.1. DLS and Zeta Potential Studies. Figure 1 shows the average hydrodynamic diameters $\left(Z_{\mathrm{av}}\right)$ determined with
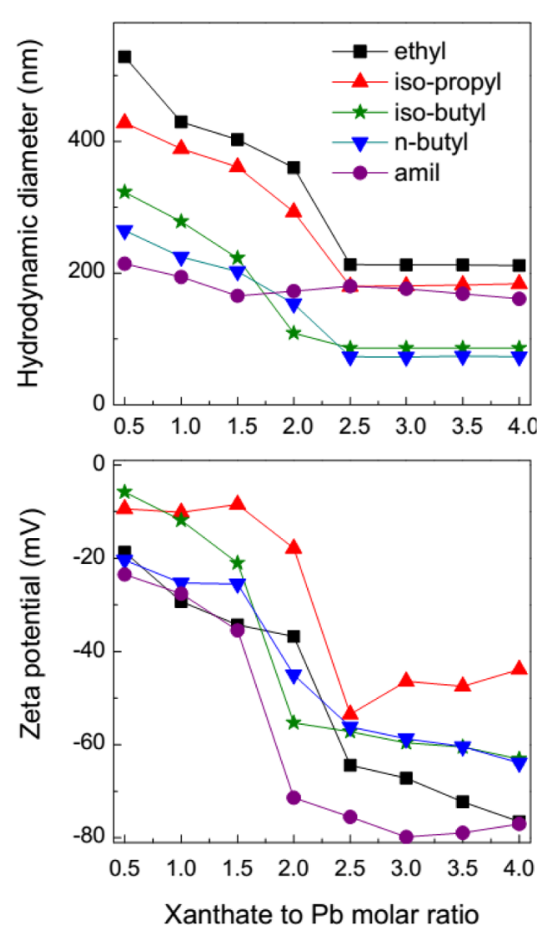

Figure 1. Effect of the initial xanthate to lead molar ratio on the hydrodynamic diameter $\left(Z_{\text {av }}\right)$ and zeta potential of colloids formed with ethyl-, iso-propyl-, iso-butyl-, $n$-butyl-, and amyl xanthates at naturally occurring $\mathrm{pHs}$ and room temperature.

dynamic light scattering (DLS) and zeta potentials of the colloids, which were produced by mixing the solutions of lead nitrate and potassium xanthate with different alkyl radicals, as a function of the xanthate to lead $(\mathrm{X} / \mathrm{Pb})$ molar ratio. The experiments were performed without adjustment of $\mathrm{pH}$ that slightly increased with the growing proportion of xanthates, for example, from $\mathrm{pH} 4.4$ to 5.2 for $n$-butyl xanthate, mainly at X/ $\mathrm{Pb}>2$ (Figure S1, Supporting Information). The hydrodynamic diameter ranged from about 50 to $500 \mathrm{~nm}$; it slowly reduced with a decrease in the excess of $\mathrm{Pb}^{2+}$, fell in the vicinity of $\mathrm{X} / \mathrm{Pb}=2$ that corresponds to the stoichiometry of the reaction

$$
\mathrm{Pb}^{2+}+2 \mathrm{R}-\mathrm{O}-\mathrm{C}(\mathrm{S}) \mathrm{S}^{-} \rightarrow \mathrm{Pb}[\mathrm{S}(\mathrm{S}) \mathrm{C}-\mathrm{O}-\mathrm{R}]_{2}
$$

and remained almost constant at higher xanthate concentrations. A negative correlation between $Z_{\mathrm{av}}$ and the size of the xanthate alkyl radical is very apparent for the xanthate-deficient solutions with $\mathrm{X} / \mathrm{Pb}<2$. It is noteworthy that the hydrodynamic diameter of lead amyl xanthate particles $(200-150 \mathrm{~nm})$ only slightly decreased over the whole range of the $\mathrm{X} / \mathrm{Pb}$ ratio.

Zeta potentials of the colloids were negative even at a large excess of $\mathrm{Pb}^{2+}$ and also showed a sudden change near the $\mathrm{X} / \mathrm{Pb}$ ratio of 2 . However, the effect of alkyl chains on zeta potential values was not straightforward, probably due to structural differences of the lead xanthates. ${ }^{12,39,40,42}$ Nevertheless, a comparison of the effects of alkyl chains and the $\mathrm{X} / \mathrm{Pb}$ ratios on $Z_{\text {av }}$ and zeta potential suggests that the surface charge and aggregation of the particles are not a major factor affecting the diameter of the colloids.

Further results are presented for lead $n$-butyl xanthate; the data for other xanthates of lead were generally similar. The hydrodynamic diameter and zeta potential of the $\mathrm{Pb}(\mathrm{BX})_{2}$ colloids prepared using stoichiometric or excessive quantities of xanthate weakly depend on $\mathrm{pH}$ (Figure 2), except for
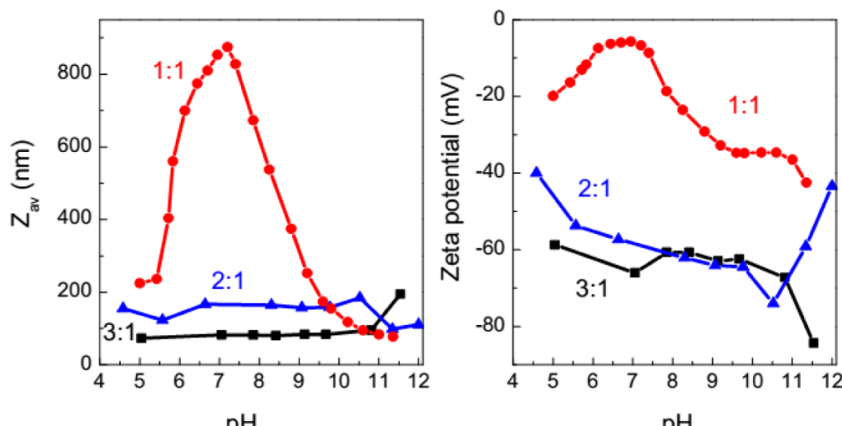

Figure 2. Effect of $\mathrm{pH}$ on the hydrodynamic diameter $\left(Z_{\mathrm{av}}\right)$ and zeta potential of lead $n$-butyl xanthate colloids prepared with the initial xanthate to $\mathrm{Pb}$ molar ratios of $1: 1,2: 1$, and $3: 1$.

instabilities at high pHs likely caused by hydrolysis. ${ }^{41}$ The behavior of the reaction media with the $\mathrm{BX}^{-}$to $\mathrm{Pb}^{2+}$ proportion of 1 , that is, with a rather big overstoichiometric amount of lead, is more complicated. The pronounced $Z_{\mathrm{av}}$ maximum and the reduction of negative zeta potential magnitude to less than $10 \mathrm{mV}$ at $\mathrm{pH}$ 6-8 imply aggregation of the colloidal particles induced by a decrease of the surface charge owing to the adsorption of $\mathrm{Pb}^{2+}$ cations. Moreover, as it will be demonstrated below, these phenomena at higher $\mathrm{pH}$ can be rationalized in terms of splitting off one xanthate ligand and fast partial decomposition of the species formed (marked as $\mathrm{PbBX}$ ), yielding lead sulfide. This is visible with the naked eye as a sol darkening and then sedimentation of a black $\mathrm{PbS}$ residue; a contribution of some lead hydroxide or basic lead nitrate precipitates also cannot be ruled out.

Typically, $\mathrm{PbX}_{2}$ sols are stable for several hours at least, with the size of the particles increased with time, particularly at lower relative concentrations of xanthate (Figure 3a). $Z_{\text {av }}$ also grows with an increase in temperature of the solutions, resulting in the appearance of micrometer entities at the BX/ $\mathrm{Pb}$ ratio of 1 . Furthermore, even at the stoichiometric reagent proportion of $2: 1$, the dynamic scattering intensity reduces with time at the temperature of $40^{\circ} \mathrm{C}$ and higher (Figure $3 \mathrm{c}$ ), indicating that the growth of $Z_{\mathrm{av}}$ is accompanied by coagulation and precipitation of the colloid and/or hydrolytic decomposition of lead xanthate. The hydrodynamic diameter increases with increasing concentration of hydrosols; nevertheless, the colloidal solutions of $n$-butyl xanthate of lead 

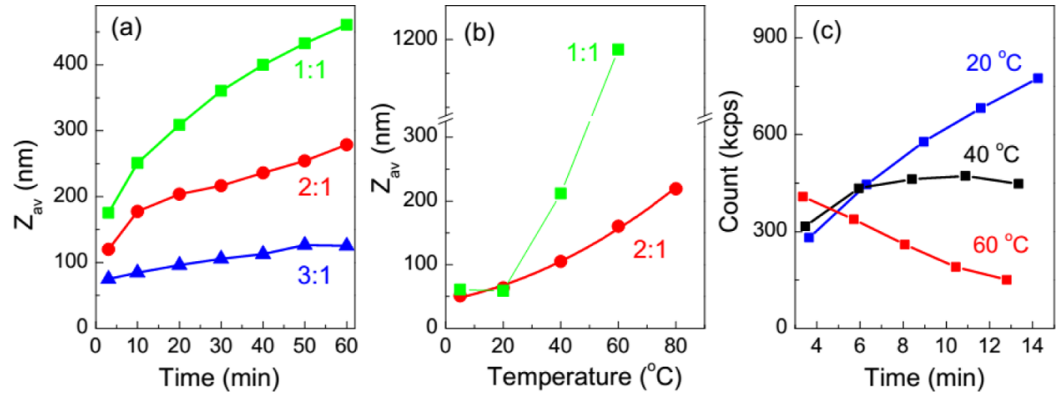

Figure 3. (a) Hydrodynamic diameter of the colloids produced with the initial $n$-butyl xanthate to lead molar ratios of 1:1, 2:1, and 3:1 as a function of the reaction time at $20^{\circ} \mathrm{C}$; (b) effect of solution temperature on $Z_{\text {av }}$ after 5 min reaction; (c) intensity of DLS measured at various temperatures for the media with the $\mathrm{BX}^{-}$to $\mathrm{Pb}^{2+}$ ratio of 2 .

remain quite stable at the lead concentration as high as $10 \mathrm{mM}$ at room temperature (Figure S2, Supporting Information).

2.2. UV-Vis Absorption Spectroscopy. Figure 4 shows $\mathrm{UV}$-vis spectra collected from the aqueous solution of $\mathrm{KBX}$

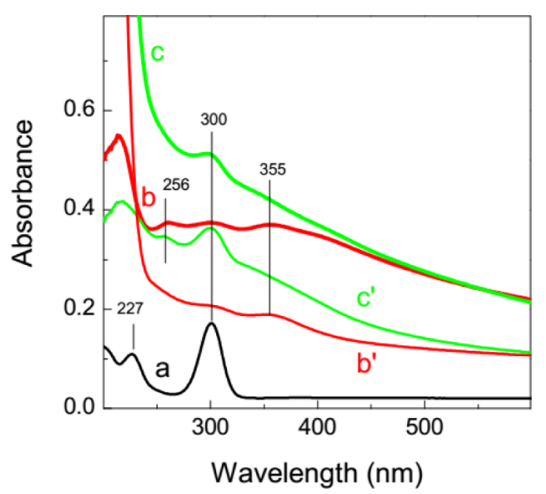

Figure 4. UV-vis absorption spectra of the solution of (a) $0.1 \mathrm{mM}$ $\mathrm{KBX}$ and reaction media with the initial $n$-butyl xanthate to lead molar ratios of $\left(b^{\prime}, b^{\prime}\right) 2: 1$ and $\left(c, c^{\prime \prime}\right) 1: 1$ at $\mathrm{pH} 9.5$ after $10 \min (b, c)$ and $120 \min \left(\mathrm{b}^{\prime}, \mathrm{c}^{\prime}\right)$ at $20^{\circ} \mathrm{C}$, respectively.

and reaction media with the $\mathrm{BX} / \mathrm{Pb}$ ratios of $2(\mathrm{pH} 5)$ and 1 ( $\mathrm{pH}$ 9.5). The spectrum of potassium xanthate has absorption maxima at 227 and $\sim 300 \mathrm{~nm}$, which can be assigned to the $\mathrm{n}-\sigma^{*}$ electron transition in the $\mathrm{C}=\mathrm{S}$ group and the $\pi-\pi^{*}$ transition in the $\mathrm{O}-\mathrm{C}-(\mathrm{S}) \mathrm{S}$ group, respectively. ${ }^{41,48,49}$ These maxima decreased, and new features at 256 and $355 \mathrm{~nm}$ attributable to modified $\mathrm{C}-\mathrm{S}$ bonds and $\mathrm{C}-\mathrm{S}-\mathrm{Pb}$ bonding, ${ }^{40}$ respectively, emerge upon the xanthate reaction with $\mathrm{Pb}^{2+}$ ions and persist during the aging of the hydrosols. In the spectra of the media with $\mathrm{BX} / \mathrm{Pb}=1$ at $\mathrm{pH} 9.5$, the maximum at $300 \mathrm{~nm}$ is stronger and increases with time, and the one at $380 \mathrm{~nm}$ is weaker than at the $\mathrm{BX} / \mathrm{Pb}$ ratio of 2 . These differences may be interpreted in terms of a higher amount of free xanthate yielded via hydrolysis of lead xanthate and a lower number of $\mathrm{Pb}-\mathrm{S}(\mathrm{S})-\mathrm{C}-$ bonds because of a different composition of the lead xanthate.

2.3. Thermal Behavior of Deposited Lead Xanthates. The results of thermogravimetric analysis (TGA) and differential scanning calorimetry (DSC) are presented in Figure 5 for lead $n$-butyl xanthates precipitated from their hydrosols. The profiles recorded for $\mathrm{Pb}(\mathrm{BX})_{2}$ prepared with the different reagent ratios were very similar and were in reasonable agreement with those reported previously. ${ }^{6-12}$ The decomposition of $\mathrm{Pb}(\mathrm{BX})_{2}$ to $\mathrm{PbS}$ as the final product in the inert atmosphere starts at about $110{ }^{\circ} \mathrm{C}$ after the melting point at 84
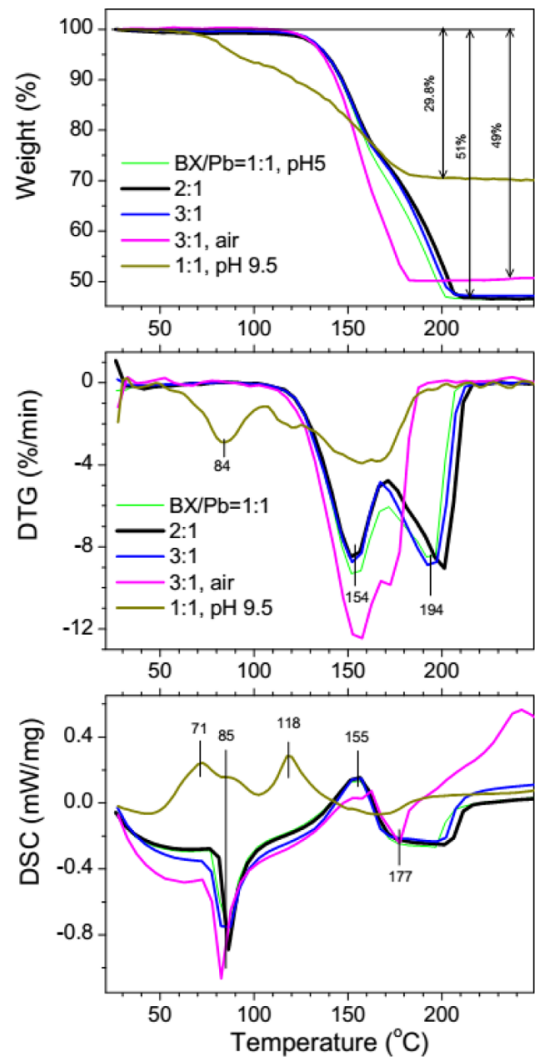

Figure 5. TG, differential TG, and DSC profiles for lead $n$-butyl xanthates precipitated from the media with the $\mathrm{BX} / \mathrm{Pb}$ ratios of $1: 1$, 2:1, and 3:1 ( $\mathrm{pH} \mathrm{5)}$ heated in the inert Ar atmosphere, 3:1 heated in air, and 1:1 at $\mathrm{pH} 9.5$ heated in Ar.

${ }^{\circ} \mathrm{C}$ and proceeds in the liquid phase ${ }^{12}$ via a two-stage reaction with two peaks at the derivative weight loss curves at 154 and $194{ }^{\circ} \mathrm{C}$, corresponding to exo- and endothermic processes. The total weight loss was about $51 \%$ that is slightly larger than the theoretical value of $47.4 \%$; this, as well as slightly higher temperature of the decomposition offset as compared with lead xanthates synthesized in nonaqueous media and reacted in one stage, ${ }^{11,12}$ may be due to wetting of the nanoparticulate material explored here. Interestingly, the reaction in air proceeded practically in one stage with the weight loss of $49 \%$ and was completed at a lower temperature (Figure 5). The sample deposited from the medium with the $\mathrm{BX} / \mathrm{Pb}$ ratio of 1:1 ( $\mathrm{pH} 9.5)$ began to decompose in the Ar atmosphere at the temperature as low as $60{ }^{\circ} \mathrm{C}$, that is, in the solid state, in several exothermic stages with a weight loss of $\sim 6 \%$ before the 
melting of minor $\mathrm{Pb}(\mathrm{BX})_{2}$ and about $24 \%$ more as the reaction completed at $\sim 180{ }^{\circ} \mathrm{C}$. The total weight loss of $\sim 30 \%$ is close to the loss of $32.6 \%$ expected for the transformation of monodentate lead xanthate $\mathrm{PbBX}$, or $\mathrm{Pb}\left[(\mathrm{SSCO}) \mathrm{C}_{4} \mathrm{H}_{9}\right]$, to $\mathrm{PbS}$ as the solid product.

2.4. FTIR and Raman Spectroscopy. Fourier transform infrared (FTIR) spectra (Figure 6) of the $\mathrm{Pb}(\mathrm{BX})_{2}$ particles

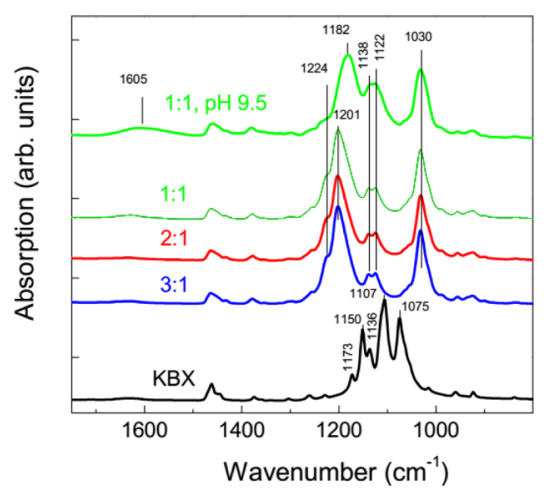

Figure 6. FTIR spectra of solid potassium $n$-butyl xanthate (KBX) and lead $n$-butyl xanthates precipitated from the hydrosols with the $\mathrm{BX} / \mathrm{Pb}$ ratios of $3: 1,2: 1$, and $1: 1(\mathrm{pH} \mathrm{5})$ and of $1: 1(\mathrm{pH} 9.5)$.

immobilized from the hydrosols with $\mathrm{pH} 5$ and the $\mathrm{BX} / \mathrm{Pb}$ ratio varying from $1: 1$ to $3: 1$ were essentially similar and distinct from $\mathrm{KBX}$; detailed interpretation of the spectra can be found in refs. ${ }^{21,22,28,38,44,45}$ The main change of the spectrum from the sample prepared at $\mathrm{BX} / \mathrm{Pb}=1$ in the alkaline solution of stationary $\mathrm{pH}=9.5$ is a shift of the peak at $1201 \mathrm{~cm}^{-1}$, which is due to antisymmetric stretch vibration $\nu_{\text {as }}$ (COC), to $1182 \mathrm{~cm}^{-1}$, while the frequency of $\nu_{\text {as }}(\mathrm{SCS})$ remains almost the same $\left(\sim 1030 \mathrm{~cm}^{-1}\right)$.

Raman scattering spectra are given in Figure 7; it should be mentioned that the baseline of the spectra is affected by sample

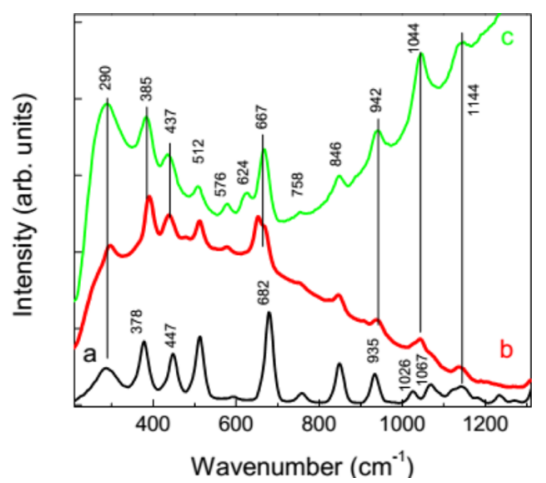

Figure 7. Raman spectra of (a) potassium $n$-butyl xanthate (KBX) and lead $n$-butyl xanthates precipitated from their hydrosols with the initial $\mathrm{BX} / \mathrm{Pb}$ ratios of (b) 2:1 (pH 5) and (c) 1:1 (pH 9.5).

fluorescence. The spectra showed the main differences between the products of the reactions at $\mathrm{pH} 5$ and 9.5 in the symmetric stretches $\nu_{\mathrm{s}}(\mathrm{SCS})$ near $660 \mathrm{~cm}^{-1}$ and small shifts of the scissoring deformation $\delta_{\text {as }}(\mathrm{SCS})$ at $385 \mathrm{~cm}^{-1}$ and symmetric stretching $\nu_{s}(\mathrm{SCS})$ near $1044 \mathrm{~cm}^{-1}$. 38,50,51 These findings indicate some modification of $\mathrm{Pb}-\mathrm{SSCOC}$ bonds, which, nevertheless, were preserved in the substance produced with the deficit of xanthate at high $\mathrm{pH}$ and are in accord with the $\mathrm{PbBX}$ composition.
2.5. X-ray Photoelectron Spectroscopy. Figure 8 represents selected photoelectron spectra of lead butyl

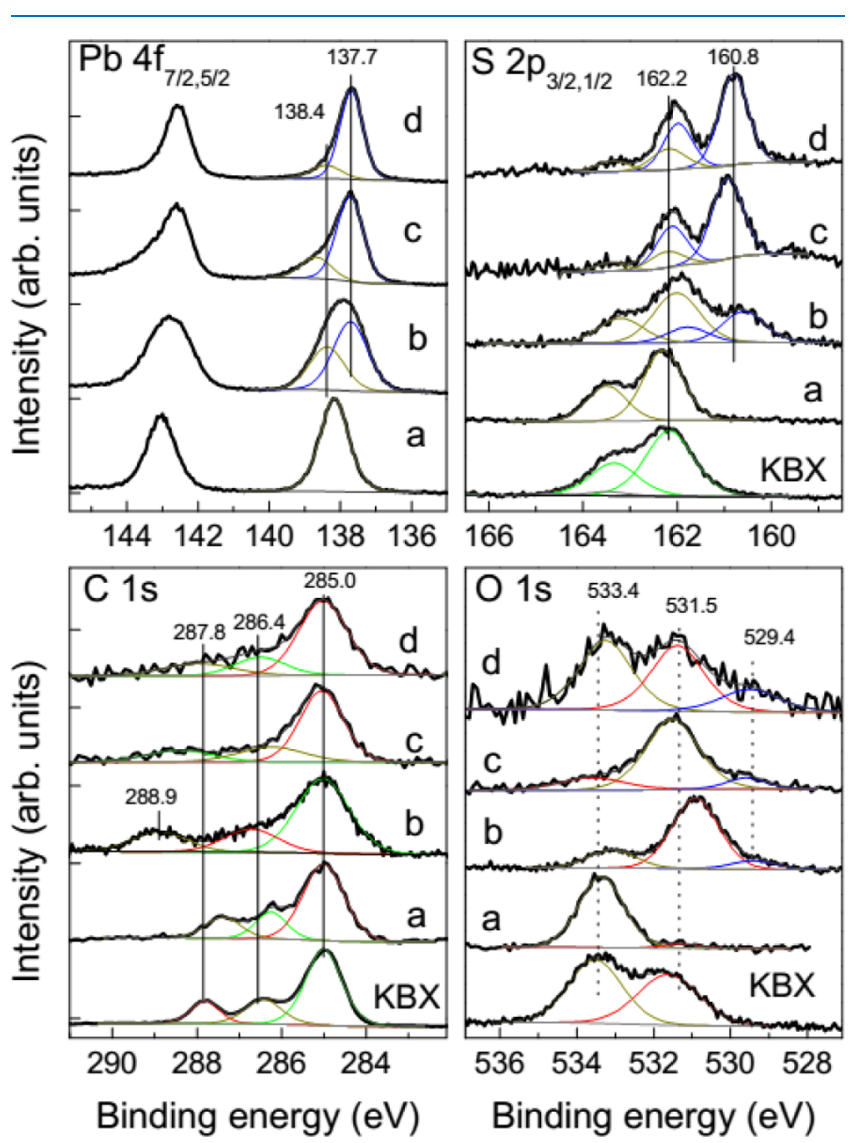

Figure 8. X-ray photoelectron spectra (normalized in height) from solid potassium $n$-butyl xanthate (KBX), lead $n$-butyl xanthates deposited from their hydrosols with the initial $\mathrm{BX} / \mathrm{Pb}$ ratios of (a) 2:1 (pH 5), (b) 1:1 (pH 9.5), and the sample (b) heated to (c) 50 and (d) $150{ }^{\circ} \mathrm{C}$ in the $\mathrm{Ar}$ atmosphere.

xanthates obtained using the $\mathrm{BX} / \mathrm{Pb}$ ratios of $2(\mathrm{pH} 5)$ and 1 ( $\mathrm{pH}$ 9.5) in comparison with the solid KBX reagent. Concentrations of elements and fitting details for these and additional spectra are given in Table S1 (Supporting Information). The spectrum of $\mathrm{KBX}$ shows the major $\mathrm{S}$ $2 p_{3 / 2,1 / 2}$ doublet with a binding energy (BE) of $S 2 p_{3 / 2}$ peak at $162.3 \mathrm{eV}$, implying that $\mathrm{S}$ atoms are equivalent; minor contributions at 163.2 and $168.2 \mathrm{eV}$ are probably due to an impurity of thiosulfate. The $\mathrm{O} 1 \mathrm{~s}$ band shows the maximum from oxygen in xanthate at $533.4 \mathrm{eV}$ and a smaller one at 531.7 $\mathrm{eV}$ attributable to an admixture of $\mathrm{KOH}^{43}$ In addition to the line from the alkyl radical in xanthate and possible carbonaceous contaminations $(285.0 \mathrm{eV})$, the $\mathrm{C} 1 \mathrm{~s}$ spectra contain almost equal maxima at 286.3 and $287.8 \mathrm{eV}$, corresponding to $\mathrm{C}^{*}$ and $\mathrm{C}^{* *}$ atoms in the $-\mathrm{C}^{*}-\mathrm{O}-\mathrm{C}^{* *}-(\mathrm{S}) \mathrm{S}$ group, respectively. ${ }^{22-27,43}$

The $\mathrm{C}$ 1s spectrum from $\mathrm{Pb}(\mathrm{BX})_{2}$ is similar, but the signal of $\mathrm{C}^{* *}$ atoms is shifted to a lower $\mathrm{BE}$ of $287.4 \mathrm{eV}$, suggesting a higher electron density at the atom because of binding of the dithionic group to $\mathrm{Pb}^{2+}$ cations instead of $\mathrm{K}^{+}$. We observed single $\mathrm{S} 2 \mathrm{p}(162.2 \mathrm{eV}), \mathrm{Pb} 4 \mathrm{f}\left(\mathrm{Pb} 4 \mathrm{f}_{7 / 2}\right.$ peak at $\left.138.3 \mathrm{eV}\right)$, and $\mathrm{O} 1 \mathrm{~s}(533.4 \mathrm{eV})$ components, with the $\mathrm{S} / \mathrm{Pb}$ atomic ratio of $\sim 4$ and the $\mathrm{O} / \mathrm{Pb} \sim 2$ (Table $\mathrm{S} 1$ ), in agreement with the $\mathrm{Pb}(\mathrm{BX})_{2}$ composition. $^{22-27,43}$ The initial xanthate to lead proportion in the media of $\mathrm{pH} 5$ had no effect on the spectra. 

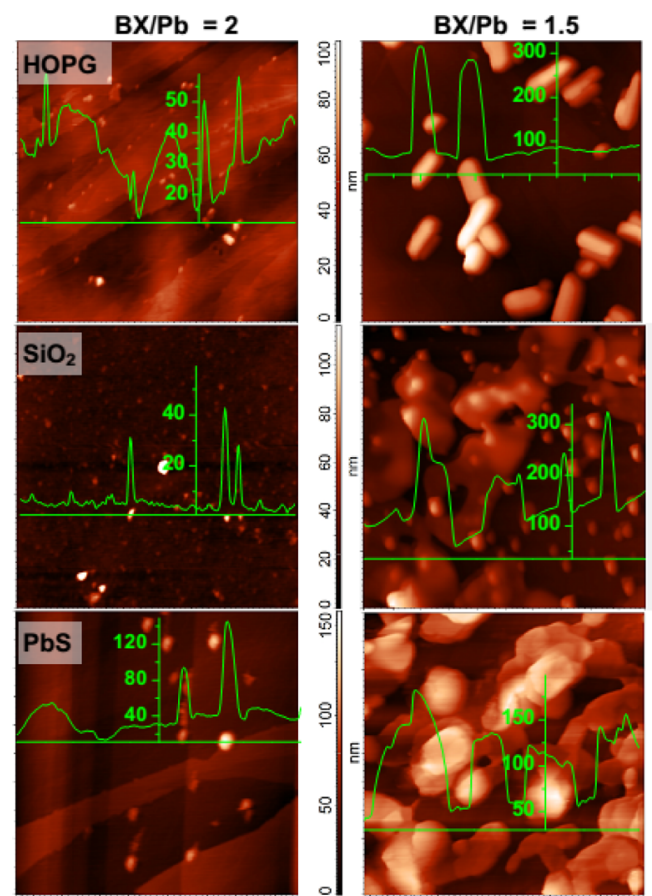

$\mathrm{BX} / \mathrm{Pb}=1, \mathrm{pH} 9.5$

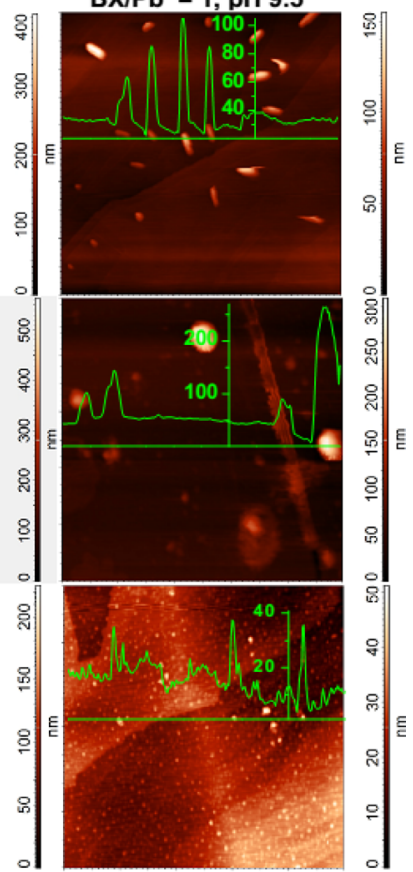

Figure 9. Tapping-mode AFM images $(5 \mu \mathrm{m} \times 5 \mu \mathrm{m})$ of the products immobilized on $\mathrm{HOPG}, \mathrm{SiO}_{2}$, and PbS surfaces treated for 2 min by the aqueous media with the $n$-butyl xanthate to lead molar ratios of 2, 1.5 at $\mathrm{pH} 5$, and 1 at $\mathrm{pH} 9.5$ (the concentration of $\mathrm{Pb}$ was $0.1 \mathrm{mM}, 20{ }^{\circ} \mathrm{C}$ ).

However, for the xanthate to lead proportion of 1:1 at $\mathrm{pH} 9-$ 10 , both the $\mathrm{S} / \mathrm{Pb}$ and $\mathrm{O} / \mathrm{Pb}$ atomic ratios were between 1 and 2. The $S 2 p$ spectra could be better fitted with the band at $162.2 \mathrm{eV}$ from $\mathrm{S}$ in xanthate and the second smaller one at $160.6 \mathrm{eV}$ from $\mathrm{PbS}$, while the $\mathrm{Pb} 4 \mathrm{f}$ spectrum can be fitted with components at 137.7 and $138.4 \mathrm{eV}$ attributable to $\mathrm{PbS}$ and lead xanthate and/or lead hydroxide, respectively. The total content of oxygen increases about two times; in addition to the $\mathrm{O} 1 \mathrm{~s}$ line of xanthate $(533.4 \mathrm{eV})$, the strong maximum at $\sim 531$ $\mathrm{eV}$ (70\% of intensity) could be assigned to hydroxide $\mathrm{OH}$ species, and a minor component at $529.5 \mathrm{eV}$ originates from $\mathrm{O}^{2-}$ in $\mathrm{PbO}$ or similar compounds. X-ray diffraction (XRD) analysis (Figure S3, Supporting Information) revealed one of such crystalline substances to be $\mathrm{Pb}_{13} \mathrm{O}_{8}(\mathrm{OH})_{6}\left(\mathrm{NO}_{3}\right)_{4} \cdot{ }^{52} \mathrm{~A}$ shift of the $\mathrm{C} 1 \mathrm{~s}$ component from 287.5 to $288.3 \mathrm{eV}$ indicates a lesser electron density (more positive charge) localized at the $\mathrm{C}^{* *}$ atom, whereas the signal from $\mathrm{C}^{*}$ atoms almost maintained its relative intensity and position. The findings indicate that the sample is composed of a mixture of $\mathrm{PbBX}$, $\mathrm{PbS}$ as a product of its decay, and some $\mathrm{Pb}-\mathrm{O}$ compounds formed from unreacted aqueous lead cations, hydrolysis of $\mathrm{PbBX}$, or surface oxidation of $\mathrm{PbS}$. The spectra acquired at liquid nitrogen ( $\mathrm{LN}$ ) temperature to arrest the decay of lead xanthates showed a higher concentration of $S$, smaller quantities of oxygen, and intensities of the $\mathrm{Pb} 4 \mathrm{f}$ lines from lead oxide and hydroxides (Table S1), so the oxidized lead species appeared to form largely ex situ.

The spectra of the $\mathrm{Pb}(\mathrm{BX})_{2}$ (not given in figures) and $\mathrm{PbBX}$ samples (Figure $8 \mathrm{c}$,d, note the changes of the $\mathrm{O} / \mathrm{Pb}$ and $\mathrm{S} / \mathrm{Pb}$ proportions in Table S1) heated in the inert atmosphere under conditions of the TGA experiment showed predominant signals of $\mathrm{PbS}$ and minor amounts of remaining lead xanthate and $\mathrm{Pb}-\mathrm{O}$ species at both 50 and $150{ }^{\circ} \mathrm{C}$ in the case of $\mathrm{PbBX}$.

2.6. Microscopic Studies. Transmission electron microscopy (TEM), electron diffraction, and energy-dispersive X-ray (EDX) examination (Supporting Information) revealed $\sim 5 \mathrm{~nm}$ particles of $\mathrm{PbS}$ and less contrast material even in the case of $\mathrm{Pb}(\mathrm{BX})_{2}$ products. The decay of poorly crystalline $\mathrm{Pb}(\mathrm{BX})_{2}$ was accelerated under the electron beam, so reliable information was not obtained from TEM.

Figure 9 shows representative tapping-mode atomic force microscopy (AFM) images of particles uptaken from various hydrosols on highly oriented pyrolytic graphite (HOPG), silica $\left(\mathrm{SiO}_{2}\right.$ on oxidized $\mathrm{Si}$ crystal), and mineral galena $(\mathrm{PbS})$. The number of the particles attached at the substrates from the media with the $\mathrm{BX} / \mathrm{Pb}$ ratios of 2 or higher is rather low, and their lateral dimensions and height agree with the hydrodynamic diameters 50-100 $\mathrm{nm}$ determined using DLS. The quantities, size, and shape of the particles deposited from the media with overstoichiometric concentration of $\mathrm{Pb}^{2+}$ depend on $\mathrm{pH}$ and the nature of the substrate. Rod-shaped particles were observed at hydrophobic inert HOPG surfaces. Both nanoparticles of 50-100 nm, often slightly elongated, and 50$100 \mathrm{~nm}$ thick irregular micrometer-scale islands were found at $\mathrm{SiO}_{2}$ and $\mathrm{PbS}$; the species can form two or even more layers of $\sim 100 \mathrm{~nm}$ in thickness. The relative area of the film was usually larger at galena; minor islands were also found at HOPG treated with the solution with the $\mathrm{BX} / \mathrm{Pb}$ ratio of 2 after aging the reaction media and longer deposition times.

Particles uptaken on HOPG from the medium with the BX/ $\mathrm{Pb}$ ratio of 1 and $\mathrm{pH} 9.5$ were mainly rod-shaped but rarer and smaller than those formed at $\mathrm{pH}$ 5. A small number of particles of $100-300 \mathrm{~nm}$ in diameter at silica became smaller with time upon their drying and likely decomposition of $\mathrm{PbBX}$ to $\mathrm{PbS}$. At galena, nanometer-scale surface roughness and particles seem to be products of oxidation of the PbS surface ${ }^{53-55}$ rather than lead xanthate entities, whose quantity was negligible.

\section{DISCUSSION}

3.1. Formation of Lead Xanthate Nanoparticles. The direct interaction of lead cations with xanthate anions $\mathrm{X}^{-}$ produces colloidal nanoparticles of $\mathrm{PbX}_{2}$ composition at $\mathrm{pH}$ 
ranging from 4 to 9 regardless of the $\mathrm{X}^{-}$to $\mathrm{Pb}^{2+}$ ratios. Although the magnitude of zeta potential depends on the ratio showing the typical curve shape with a sharp decrease nearby the stoichiometry point, the potential remained negative even at the large excess of the cation in contrast to copper xanthate nanoparticles (in fact, a composite $\mathrm{CuX} / \mathrm{X}_{2}$ ), ${ }^{46,47}$ whose surface charge changed its sign near the $\mathrm{X}^{-} / \mathrm{Cu}^{2+}=2$. The hydrodynamic diameter of the colloids depends not only on zeta potential and aggregation of particles but also on the nature of alkyl radicals and the structural factors ${ }^{12}$ related with the hydrophobicity and solubility of $\mathrm{Pb}$ xanthates. These colloids show rather high chemical and aggregative stability during many hours at ambient temperature and $\mathrm{pH}$ values typical, particularly, for the flotation of lead-bearing ores, and their occurrence should be taken into account in the wastewater treatment processes.

The hydrosols formed with overstoichiometric cations at $\mathrm{pH}$ higher than $\sim 9$ exhibit a very different behavior. It has been proposed on the basis of thermodynamic and mechanistic consideration $^{20}$ that basic lead xanthates $\mathrm{Pb}(\mathrm{OH}) \mathrm{X}$ form in such alkaline slurries. Experimentally, the presence of $\mathrm{Pb}$ $(\mathrm{OH}) \mathrm{BX}$ on galena treated with lead-saturated $n$ - and $i$-butyl xanthate solutions of $\mathrm{pH} 9.2$ has been suggested from the ratio of $\sim 2$ of corresponding XPS $\mathrm{S} / \mathrm{Pb}$ signals, ${ }^{24,25}$ although the results of time-of-flight secondary ion mass spectroscopy ${ }^{25}$ were not conclusive. The spectroscopic, XRD, and TGA data in the current research imply that the composition of the colloidal particles was $\mathrm{PbBX}$, rather than $\mathrm{Pb}(\mathrm{OH}) \mathrm{BX}$, with an admixture of basic lead nitrate, lead hydroxide, and $\mathrm{PbS}$ formed upon aging and drying the solution. The species is also distinct from an intermediate $\mathrm{Pb}(\mathrm{SH}) \mathrm{BX}$, which has been proposed $^{12}$ to form in the thermal decomposition of $\mathrm{Pb}(\mathrm{BX})_{2}$, via breakaway of one xanthate ligand; this requires the $\mathrm{S} / \mathrm{Pb}$ ratio to be 3 , but that is not the case here. It is interesting to note that the distortions of the chemical bonds observed in the $>\mathrm{C}-\mathrm{O}-\mathrm{C}-$ group are large and may be indicative of additional $\mathrm{Pb}-\mathrm{O}$ bonding, including polymerization; the composition and structure of "PbBX" need further investigation. However, the "PbBX" species has much less thermal stability than normal lead xanthates $\mathrm{PbX}_{2}$ and starts to decompose to $\mathrm{PbS}$ in the inert atmosphere at the temperature as low as $60{ }^{\circ} \mathrm{C}$ in the solid state in contrast to $\mathrm{Pb}(\mathrm{BX})_{2}$ and other metal xanthates which start decomposing after the melting. This could be of interest, for example, for a lowtemperature preparation of polymer composites incorporating metal sulfide nanoparticles.

3.2. Immobilization of Lead Xanthate Nanoparticles. Colloidal lead xanthates spontaneously arisen in the flotation slurries could interact with mineral surfaces and affect their floatability; the uptake of the lead species is also important for environmental issues. The number of immobilized nanoparticles of $\mathrm{PbX}_{2}$ was low (Figure 9) when the solutions contained excessive xanthate and the substrates were negatively charged that is typical for metal sulfides (galena, etc.), silica, and many other gangue minerals. Consequently, the effect of $\mathrm{PbX}_{2}$ on flotation should be insignificant, and floatability of galena is determined by the chemisorbed xanthate, as it has been established in previous studies. ${ }^{19,23-26}$ When the aqueous medium was enriched in lead cations, we observed the micrometer-scale layers composed of $\mathrm{PbX}_{2}$ nanoparticles, which covered large areas, probably because adsorption of $\mathrm{Pb}^{2+}$ induced a positive surface charge of the supports. This mechanism is inactive at inert HOPG with a small number of surface groups for lead cations. Instead, spatially nonuniform adsorption of cations onto lead xanthate nanoparticles may be a reason behind the formation of rod-shaped particles. ${ }^{56}$ The situation reverses again at high $\mathrm{pH}$ when the number of $\mathrm{OH}^{-}$ groups on the mineral surface increases, while aqueous lead cations are bounded in anionic hydroxide complexes or precipitated, so the layers of immobilized nanoparticles do not emerge (Figure 9). Nevertheless, the galena surface becomes essentially hydrophobic under these conditions according to contact angle measurement (data are not presented here). The layers of immobilized lead xanthate nanoparticles can be used, for example, as a precursor for controlled deposition of $\mathrm{PbS}$ films or other materials.

\section{CONCLUSIONS}

Colloidal particles of lead xanthates formed via direct interaction of aqueous lead cations and various xanthates have the $\mathrm{PbX}_{2}$ composition and the hydrodynamic diameter from 50 to $500 \mathrm{~nm}$. The diameter decreases with the increasing length of alkyl radicals and the xanthate to lead molar ratio, with an abrupt fall at the stoichiometric composition. Zeta potential behaves similarly but remains negative under all the experimental conditions in contrast to copper xanthates. The characteristics of $\mathrm{PbX}_{2}$ colloids are insignificantly affected by $\mathrm{pH}<10$, except for the species produced with a big overstoichiometric content of $\mathrm{Pb}^{2+}$. The composition of colloidal particles formed in the alkaline media of $\mathrm{pH}=9.5$ with the $\mathrm{Pb}$ excess is close to $\mathrm{PbX}$ but not $\mathrm{Pb}(\mathrm{OH}) \mathrm{X}$ as suggested earlier. The "PbX" species easily decayed, yielding $\mathrm{PbS}$ in aqueous media and air; under heating in an inert atmosphere, a solid-state reaction started at $50-60{ }^{\circ} \mathrm{C}$, while the solid $\mathrm{PbX}_{2}$ decomposed at the temperatures above $100{ }^{\circ} \mathrm{C}$ after the melting. The decomposition of the precipitated $\mathrm{PbX}_{2}$ colloids is shifted to slightly higher temperatures in comparison with the bulk material prepared in nonaqueous media ${ }^{12}$ and proceeds in two stages. The uptake of the nanoparticles of lead xanthates onto HOPG, $\mathrm{PbS}$, and $\mathrm{SiO}_{2}$ surfaces from the solutions having excess of xanthate was rather low because of the negative charges of both the $\mathrm{PbX}_{2}$ nanoparticles and supports. This is also valid for " $\mathrm{PbX}$ " particles prepared with the $\mathrm{BX} / \mathrm{Pb}$ ratio of 1 at $\mathrm{pH}$ 9.5. The $\mathrm{PbX}_{2}$ colloids from the media with the $\mathrm{BX} / \mathrm{Pb}$ ratios less than 2 and $\mathrm{pH}<9$ spontaneously form micrometer-size islands on $\mathrm{PbS}$ and $\mathrm{SiO}_{2}$, probably due to adsorption of excessive aqueous $\mathrm{Pb}^{2+}$ cations inducing a positive charge of the support. The thickness of the islands of 50-100 nm correlates with the diameter of $\mathrm{PbX}_{2}$ nanoparticles. Rod-shaped particles but not the islands deposit onto HOPG, possibly because a low density of surface functional groups binding $\mathrm{Pb}^{2+}$ on $\mathrm{HOPG}$ and spatially inhomogeneous adsorption of lead cations onto (immobilized) $\mathrm{PbX}_{2}$ entities promoted their coalescence to nanorods. These findings can be interesting for controlling the deposition of lead xanthates on various supports including minerals in flotation and materials science and should be taken into account for water treatment and environmental issues.

\section{EXPERIMENTAL SECTION}

5.1. Materials and Preparation Methods. Potassium ethyl xanthate $\left(\mathrm{CH}_{3} \mathrm{CH}_{2} \mathrm{OCSSK}\right)$, isopropyl xanthate ( $\left.\mathrm{C}_{2} \mathrm{H}_{6} \mathrm{CHOCSSK}\right)$, n-butyl xanthate, isobutyl xanthate $\left(\mathrm{C}_{3} \mathrm{H}_{7} \mathrm{CH}_{2} \mathrm{OCSSK}\right)$, and amyl xanthate $\left(\mathrm{C}_{4} \mathrm{H}_{9} \mathrm{CH}_{2} \mathrm{OSSK}\right)$ of 95\% purity purchased from "Volzhsky Orgsynthese" (Russia) 
were recrystallized two times in acetone and kept frozen in the solid state; the fresh solutions of the reagents were prepared using deionized water $(\sim 10 \mathrm{M} \Omega \cdot \mathrm{cm})$ immediately before the experiment. Lead nitrate and other chemicals were of analytical grade and were used as received. In a typical procedure, $1 \mathrm{~mL}$ of $\mathrm{Pb}\left(\mathrm{NO}_{3}\right)_{2}$ solution $(0.3 \mathrm{mM})$ and $1 \mathrm{~mL}$ of potassium xanthate solution, whose concentration was varied from 0.15 to $8 \mathrm{mM}$ in order to obtain a predetermined xanthate to $\mathrm{Pb}$ ratio, were added to $1 \mathrm{~mL}$ of water and agitated for $5 \mathrm{~min}$ in a thermostated glass; the $\mathrm{pH}$ was adjusted to a required value using $1 \mathrm{mM} \mathrm{KOH}$ solution when necessary. The hydrosols of "PbX" species were obtained by mixing the solutions of $\mathrm{Pb}\left(\mathrm{NO}_{3}\right)_{2}$, potassium $n$-butyl xanthate $(\mathrm{KBX})$, and $\mathrm{KOH}$ in the molar proportions $1: 1: 1$; the $\mathrm{pH}$ of the medium formed was stabilized at 9.5. Then the reaction solutions were loaded into a cell for UV-vis absorption spectroscopy, DLS, or zeta potential studies.

5.2. Thermogravimetry Analysis. The samples of lead xanthates for TGA were precipitated from the $1 \mathrm{mM}$ colloidal solutions by centrifugation at $10 \mathrm{~g}$ for $10 \mathrm{~min}$, washed with water by decantation, and dried on a filter paper in air at room temperature. TGA and DTA were performed in the range from the ambient temperature to $900{ }^{\circ} \mathrm{C}$ using a STA449 F1 Jupiter instrument (Netzsch) at the heating rate of $10{ }^{\circ} \mathrm{C} / \mathrm{min}$ in argon at a gas flow rate of $50 \mathrm{~mL} / \mathrm{min}$; some experiments were also conducted in air.

5.3. Characterization. UV-vis absorption spectra were collected in a thermostatic quartz cell with the optical path of 1 $\mathrm{cm}$ employing an Evolution 300 spectrometer (Thermo Scientific) or a Shimadzu UV 3600 instrument. The mean hydrodynamic diameter $\left(Z_{\mathrm{av}}\right)$ and zeta potential of the colloids were determined by DLS using a Zetasizer Nano ZS spectrometer (Malvern Instruments Ltd., UK) at the scattering angle $173^{\circ}$ in a folded polystyrene cell or polycarbonate cell with $\mathrm{Pd}$ electrodes after about $10 \mathrm{~min}$ reaction, unless otherwise stated.

FTIR spectra were recorded from the lead xanthates precipitated and dried as described above in $\mathrm{KBr}$ pellets with a Bruker VECTOR 22 Fourier spectrometer. The Raman spectra were recorded in the backscattering geometry using a HORIBA Jobin-Yvon T64000 spectrometer equipped with an LN-cooled charge-coupled device detector in subtractive dispersion mode utilizing $\mathrm{Ar}^{+}$-ion laser Spectra-Physics Stabilite 2017 ( $514.5 \mathrm{~nm}, 1 \mathrm{~mW})$ as an excitation light source.

$\mathrm{X}$-ray photoelectron spectroscopy (XPS) studies were performed using a hydrosol dried at HOPG and gently rinsed with water. The spectra were acquired using a SPECS spectrometer equipped with a PHOIBOS 150 MCD-9 analyzer at electron take-off angle $90^{\circ}$ employing monochromatic $\mathrm{Al} \mathrm{K} \alpha$ radiation $(1486.6 \mathrm{eV})$ of an $\mathrm{X}$-ray tube operated at $200 \mathrm{~W}$. The analyzer pass energy was $10 \mathrm{eV}$ for high-resolution scans and $20 \mathrm{eV}$ for survey spectra. The experiments were conducted at room temperature, and several samples were frozen in the lock chamber and measured at $-150{ }^{\circ} \mathrm{C}$ to reduce their decay. Electron flood gun was employed to eliminate inhomogeneous electrostatic charging of the samples; the $\mathrm{C} 1 \mathrm{~s}$ peak at 284.45 $\mathrm{eV}$ from HOPG was used as a reference. The high-resolution spectra were fitted after subtraction of Shirley-type background with Gaussian-Lorentzian peak profiles, including $\mathrm{Pb} \mathrm{4f_{7/2,5/2 }}$ and $S 2 p_{3 / 2,1 / 2}$ doublets with the spin-orbit splitting of 4.85 and $1.19 \mathrm{eV}$ and the branching ratios of 0.75 and 0.5 , respectively, using CasaXPS software.
TEM, EDX analysis, and selected area electron diffraction (SAED) characterization were carried out using a JEM 2100 instrument (JEOL) operated at an accelerating voltage of 200 $\mathrm{kV}$. For examination, a droplet of the aqueous media, typically after $10 \mathrm{~min}$ reaction, was placed onto a $\mathrm{Cu}$ grid with a cover layer of amorphous carbon and allowed to dry in ambient air. Tapping-mode AFM investigations were conducted in air with a multimode Solver P47 device equipped with a $14 \mathrm{~mm}$ scanner (NT-MDT, Russia) using silicon cantilevers with a resonant frequency of about $150 \mathrm{kHz}$. The samples were prepared by air-drying of a sol droplet on $\mathrm{HOPG}, \mathrm{SiO}_{2}$, or natural $\mathrm{PbS}$ (galena) supports and water-rinsing.

\section{ASSOCIATED CONTENT}

\section{S Supporting Information}

The Supporting Information is available free of charge on the ACS Publications website at DOI: 10.1021/acsomega.9b00841.

Additional data on the stability of colloids; atomic concentrations derived from XPS analysis; XRD for $\mathrm{PbBX}$ residue; and morphology and composition of immobilized products as determined with TEM, SAED, and EDX (PDF)

\section{AUTHOR INFORMATION}

\section{Corresponding Author}

*E-mail: yumikh@icct.ru.

\section{ORCID}

Alexander S. Krylov: 0000-0001-8949-0584

Yuri L. Mikhlin: 0000-0003-1801-0947

Notes

The authors declare no competing financial interest.

\section{ACKNOWLEDGMENTS}

This research was supported by Russian Science Foundation, project 18-17-00135

\section{REFERENCES}

(1) Harrison, G. H. Xanthates. In Kirk-Othmer Encyclopedia of Chemical Technology; Howe-Grant, M., Ed.; John Wiley \& Sons: New York, 1998; pp 713-734.

(2) Destarac, M.; Brochon, C.; Catala, J.-M.; Wilczewska, A.; Zard, S. Z. Macromolecular design via the interchange of xanthates (MADIX): polymerization of styrene with O-ethyl xanthates as controlling agents. Macromol. Chem. Phys. 2002, 203, 2281-2289.

(3) Wang, Y.; Li, J.; Ren, T. A potential approach to replace sulfurized olefins with borate ester containing xanthate group in lubricating oil. Sci. Bull. 2008, 53, 992-997.

(4) Vagvala, T. C.; Pandey, S. S.; Ogomi, Y.; Ma, T.; Hayase, S. Investigation of metal xanthates as latent curing catalysts for epoxy resin via formation of in-situ metal sulfides. Inorg. Chim. Acta 2015, 435, 292-298.

(5) Pradhan, N.; Katz, B.; Efrima, S. Synthesis of high-quality metal sulfide nanoparticles from alkyl xanthate single precursors in alkylamine solvents. J. Phys. Chem. B 2003, 107, 13843-13854.

(6) Lu, X.; Zhao, Y.; Wang, C. Fabrication of PbS nanoparticles in polymer-fiber matrices by electrospinning. Adv. Mater. 2005, 17, $2485-2488$

(7) Leventis, H. C.; King, S. P.; Sudlow, A.; Hill, M. S.; Molloy, K. C.; Haque, S. A. Nanostructured hybrid polymer-inorganic solar cell active layers formed by controllable in situ growth of semiconducting sulfide networks. Nano Lett. 2010, 10, 1253-1258.

(8) Clark, J. M.; Kociok-Köhn, G.; Harnett, N. J.; Hill, M. S.; Hill, R.; Molloy, K. C.; Saponia, H.; Stanton, D.; Sudlow, A. Formation of 
$\mathrm{PbS}$ materials from lead xanthate precursors. Dalton Trans. 2011, 40, 6893-6900.

(9) Lutz, T.; MacLachlan, A.; Sudlow, A.; Nelson, J.; Hill, M. S.; Molloy, K. C.; Haque, S. A. Thermal decomposition of solution processable metal xanthates on mesoporous titanium dioxide films: a new route to quantum-dot sensitised heterojunctions. Phys. Chem. Chem. Phys. 2012, 14, 16192-16196.

(10) Rath, T.; Padeste, C.; Vockenhuber, M.; Fradler, C.; Edler, M.; Reichmann, A.; Letofsky-Papst, I.; Hofer, F.; Ekinci, Y.; Griesser, T. Direct extreme UV-lithographic conversion of metal xanthates into nanostructured metal sulfide layers for hybrid photovoltaics. J. Mater. Chem. A 2013, 1, 11135-11140.

(11) Lewis, E. A.; McNaughter, P. D.; Yin, Z.; Chen, Y.; Brent, J. R.; Saah, S. A.; Raftery, J.; Awudza, J. A. M.; Malik, M. A.; O’Brien, P.; Haigh, S. J. In situ synthesis of PbS nanocrystals in polymer thin films from lead(II) xanthate and dithiocarbamate complexes: evidence for size and morphology control. Chem. Mater. 2015, 27, 2127-2136.

(12) McNaughter, P. D.; Saah, S. A.; Akhtar, M.; Abdulwahab, K.; Malik, M. A.; Raftery, J.; Awudza, J. A. M.; O’Brien, P. The effect of alkyl chain length on the structure of lead(II) xanthates and their decomposition to $\mathrm{PbS}$ in melt reactions. Dalton Trans. 2016, 45, 16345-16353.

(13) Khan, M. D.; Murtaza, G.; Revaprasadu, N.; O’Brien, P. Synthesis of chalcopyrite-type and thiospinel minerals/materials by low temperature melts of xanthates. Dalton Trans. 2018, 47, 88708873

(14) Rabkin, A.; Friedman, O.; Golan, Y. Surface plasmon resonance in surfactant coated copper sulfide nanoparticles: Role of the structure of the capping agent. J. Colloid Interface Sci. 2015, 457, 43-51.

(15) Efrima, S.; Pradhan, N. Xanthates and related compounds as versatile agents in colloid science. Compt. Rendus Chem. 2003, 6, $1035-1045$

(16) Moore, H. J.; Colorado, R., Jr.; Lee, H. J.; Jamison, A. C.; Lee, T. R. Synthesis, Characterization, and Relative Stabilities of SelfAssembled Monolayers on Gold Generated from Bidentate n-Alkyl Xanthic Acids. Langmuir 2013, 29, 10674-10683.

(17) Chang, Y.-K.; Chang, J.-E.; Lin, T.-T.; Hsu, Y.-M. Integrated copper-containing wastewater treatment using xanthate process. $J$. Hazard Mater. 2002, 94, 89-99.

(18) Mahmoud, M. R.; Lazaridis, N. K.; Matis, K. A. Study of flotation conditions for cadmium(II) removal from aqueous solutions. Process Saf. Environ. Prot. 2015, 94, 203-211.

(19) Woods, R. Chemisorption of thiols on metals and metal sulfides. In Modern Aspects of Electrochemistry; Bockris, J. O., Conway, B. E., White, R. E., Eds.; Plenum Press: New York, 1996; pp 401-453.

(20) Pålsson, B. I.; Eric Forssberg, K. S. Computer-assisted calculations of thermodynamic equilibria in the galena-ethyl xanthate system. Int. J. Miner. Process. 1988, 23, 93-121.

(21) Leppinen, J. O.; Basilio, C. I.; Yoon, R. H. In-situ FTIR study of ethyl xanthate adsorption on sulfide minerals under conditions of controlled potential. Int. J. Miner. Process. 1989, 26, 259-274.

(22) Laajalehto, K.; Nowak, P.; Suoninen, E. On the XPS and IR identification of the products of xanthate sorption at the surface of galena. Int. J. Miner. Process. 1993, 37, 123-147.

(23) Kartio, I.; Laajalehto, K.; Suoninen, E. Characterization of the ethyl xanthate adsorption layer on galena ( $\mathrm{PbS}$ ) by synchrotron radiation excited photoelectron spectroscopy. Colloids Surf., A 1999, 154, 97-101.

(24) Shchukarev, A. V.; Kravets, I. M.; Buckley, A. N.; Woods, R. Submonolayer adsorption of alkyl xanthates on galena. Int. J. Miner. Process. 1994, 41, 99-114.

(25) Buckley, A. N.; Goh, S. W.; Lamb, R. N.; Woods, R. Interaction of thiol collectors with pre-oxidised sulfide minerals. Int. J. Miner. Process. 2003, 72, 163-174.

(26) Mikhlin, Y.; Karacharov, A.; Tomashevich, Y.; Shchukarev, A. Cryogenic XPS study of fast-frozen sulfide minerals: flotation-related adsorption of $n$-butyl xanthate and beyond. J. Electron Spectrosc. Relat. Phenom. 2016, 206, 65-73.
(27) Mikhlin, Y.; Karacharov, A.; Tomashevich, Y.; Shchukarev, A. Interaction of sphalerite with potassium n-butyl xanthate and copper sulfate solutions studied by XPS of fast-frozen samples and zetapotential measurement. Vacuum 2016, 125, 98-105.

(28) Firkala, T.; Kuschewski, F.; Nörenberg, T.; Klopf, J.; Pashkin, A.; Foerstendorf, H.; Rudolph, M.; Kehr, S.; Eng, L. Near-field optical examination of potassium n-butyl xanthate/chalcopyrite flotation products. Minerals 2018, 8, 118.

(29) Koporulina, E. V.; Ryazantseva, M. V.; Chanturiya, E. L.; Zhuravleva, E. S. Butyl-xanthate adsorption on the surface of sulfide minerals under conditions of their preliminary treatment with water electrolysis products according to atomic-force microscopy and infrared Fourier spectroscopy data. J. Surf. Invest.: X-Ray, Synchrotron Neutron Tech. 2018, 12, 877-886.

(30) Krasowska, M.; Zawala, J.; Bradshaw-Hajek, B. H.; Ferri, J. K.; Beattie, D. A. Interfacial characterisation for flotation: 1. Solid-liquid interface. Curr. Opin. Colloid Interface Sci. 2018, 37, 61-73.

(31) Hofacker, A. F.; Voegelin, A.; Kaegi, R.; Weber, F.-A.; Kretzschmar, R. Temperature-dependent formation of metallic copper and metal sulfide nanoparticles during flooding of a contaminated soil. Geochim. Cosmochim. Acta 2013, 103, 316-332.

(32) Hudson-Edwards, K. A. Sources, mineralogy, chemistry and fate ofheavy metal-bearing particles in mining-affected river systems. Mineral. Mag. 2003, 67, 205-217.

(33) Hu, S.; Chen, X.; Shi, J.; Chen, Y.; Lin, Q. Particle-facilitated lead and arsenic transport in abandoned mine sites soil influenced by simulated acid rain. Chemosphere 2008, 71, 2091-2097.

(34) Auffan, M.; Bottero, J.-Y.; Chaneac, C.; Rose, J. Inorganic manufactured nanoparticles: how their physicochemical properties influence their biological effects in aqueous environments. Nanomedicine 2010, 5, 999-1007.

(35) Shahid, M.; Pinelli, E.; Dumat, C. Review of Pb availability and toxicity to plants in relation with metal speciation; role of synthetic and natural organic ligands. J. Hazard Mater. 2012, 219-220, 1-12. (36) Mikhlin, Y.; Vorobyev, S.; Romanchenko, A.; Karasev, S.; Karacharov, A.; Zharkov, S. Ultrafine particles derived from mineral processing: a case study of the $\mathrm{Pb}-\mathrm{Zn}$ sulfide ore with emphasis on lead-bearing colloids. Chemosphere 2016, 147, 60-66.

(37) Mikhlin, Y.; Romanchenko, A.; Vorobyev, S.; Karasev, S.; Volochaev, M.; Kamenskiy, E.; Burdakova, E. Ultrafine particles in ground sulfide ores: A comparison of four $\mathrm{Cu}-\mathrm{Ni}$ ores from Siberia, Russia. Ore Geol. Rev. 2017, 81, 1-9.

(38) Little, L. H.; Poling, G. W.; Leja, J. Infrared Spectra of Xanthate Compounds: Ii. Assignment of Vibrational Frequencies. Can. J. Chem. 1961, 39, 745-754.

(39) Hagihara, H.; Yamashita, S. The crystal structure of lead ethyixanthate. Acta Crystallogr. 1966, 21, 350-358.

(40) Hagihara, H.; Watanabe, Y.; Yamashita, S. The crystal structure of lead n-butylxanthate. I. Disordered structure. Acta Crystallogr., Sect. B: Struct. Crystallogr. Cryst. Chem. 1968, 24, 960-966.

(41) Sheikh, N. The chemical stability of heavy metal xanthates. Ph.D Thesis, University British Columbia, 1972.

(42) Tiekink, E. R. T.; Winter, G. Inorganic xanthates: a structural perspective. Rev. Inorg. Chem. 1992, 12, 183-230.

(43) Shchukarev, A. V.; Nichiporenko, T. O.; Mashevskiy, G. N. Xray photoelectron spectra of potassium butyl xanthate and dibutylxanthogen. Obogashch. Rud 1992, 1, 21-24.

(44) Tiekink, E. R. T.; Haiduc, I. Stereochemical aspects of metal xanthate complexes: molecular structures and supramolecular selfassembly. Prog. Inorg. Chem. 2005, 54, 127-319.

(45) Hellström, P.; Öberg, S.; Fredriksson, A.; Holmgren, A. A theoretical and experimental study of vibrational properties of alkyl xanthates. Spectrochim. Acta, Part A 2006, 65, 887-895.

(46) Vorobyev, S. A.; Saikova, S. V.; Erenburg, S. B.; Trubina, S. V.; Ivanov, Y. N.; Maksimov, N. G.; Mikhlin, Y. L. A comparative study of the structure of copper and lead xanthates. J. Struct. Chem. 2017, 58, $1144-1151$.

(47) Mikhlin, Y.; Vorobyev, S.; Saikova, S.; Tomashevich, Y.; Fetisova, O.; Kozlova, S.; Zharkov, S. Preparation and characterization 
of colloidal copper xanthate nanoparticles. New J. Chem. 2016, 40, 3059-3065.

(48) Pomianowski, A.; Leja, J. Spectrophotometric study of xanthate and dixanthogen solutions. Can. J. Chem. 1963, 41, 2219-2230.

(49) Juncal, L. C.; Tobón, Y. A.; Piro, O. E.; Della Védova, C. O.; Romano, R. M. Structural, spectroscopic and theoretical studies on dixanthogens: $(\mathrm{ROC}(\mathrm{S}) \mathrm{S})_{2}$, with $\mathrm{R}=\mathrm{n}$-propyl and isopropyl. New J. Chem. 2014, 38, 3708-3716.

(50) Andreev, G. N.; Barzev, A. Raman spectroscopic study of some chalcopyrite-xanthate flotation products. J. Mol. Struct. 2003, 661$662,325-332$.

(51) Wei, S.-L.; Gao, P.-C.; Zhao, Y.-Y.; Wang, H.-g.; Zheng, X. Photofragmentation mechanisms of nickel methyl xanthate-resonance Raman and density functional theory investigation. J. Raman Spectrosc. 2011, 42, 1025-1033.

(52) Li, Y.; Krivovichev, S. V.; Burns, P. C. Crystal chemistry of lead oxide hydroxide nitrates II. The crystal structure of $\mathrm{Pb}_{13} \mathrm{O}_{8}(\mathrm{OH})_{6}\left(\mathrm{NO}_{3}\right)_{4}$. J. Solid State Chem. 2001, 158, 74-77.

(53) Mikhlin, Y. L.; Romanchenko, A. S.; Shagaev, A. A. Scanning probe microscopy studies of $\mathrm{PbS}$ surfaces oxidized in air and etched in aqueous acid solutions. Appl. Surf. Sci. 2006, 252, 5645-5658.

(54) Mikhlin, Y. L.; Karacharov, A. A.; Likhatski, M. N. Effect of adsorption of butyl xanthate on galena, $\mathrm{PbS}$, and HOPG surfaces as studied by atomic force microscopy and spectroscopy and XPS. Int. J. Miner. Process. 2015, 144, 81-89.

(55) De Giudici, G.; Rossi, A.; Fanfani, L.; Lattanzi, P. Mechanisms of galena dissolution in oxygen-saturated solutions: Evaluation of $\mathrm{pH}$ effect on apparent activation energies and mineral-water interface. Geochim. Cosmochim. Acta 2005, 69, 2321-2331.

(56) Dempster, J. M.; de la Cruz, M. O. Aggregation of heterogeneously charged colloids. ACS Nano 2016, 10, 5909-5915. 